\title{
Retrieval of aerosol single-scattering albedo and polarized phase function from polarized sun-photometer measurements for Zanjan's atmosphere
}

\author{
A. Bayat ${ }^{1}$, H. R. Khalesifard ${ }^{1,2}$, and A. Masoumi $^{3}$ \\ ${ }^{1}$ Department of Physics, Institute for Advanced Studies in Basic Sciences (IASBS), Zanjan 45137-66731, Iran \\ ${ }^{2}$ Center for Climate Change and Global Warming, Institute for Advanced Studies in Basic Sciences (IASBS), \\ Zanjan 45137-66731, Iran \\ ${ }^{3}$ Department of Physics, Faculty of Sciences, University of Zanjan, Zanjan 45371-38791, Iran \\ Correspondence to: A. Bayat (a_bayat@iasbs.ac.ir)
}

Received: 14 March 2013 - Published in Atmos. Meas. Tech. Discuss.: 4 April 2013

Revised: 2 September 2013 - Accepted: 4 September 2013 - Published: 15 October 2013

\begin{abstract}
The polarized phase function of atmospheric aerosols has been investigated for the atmosphere of Zanjan, a city in northwest Iran. To do this, aerosol optical depth, Ångström exponent, single-scattering albedo, and polarized phase function have been retrieved from the measurements of a Cimel CE 318-2 polarized sun-photometer from February 2010 to December 2012. The results show that the maximum value of aerosol polarized phase function as well as the polarized phase function retrieved for a specific scattering angle (i.e., $\left.60^{\circ}\right)$ are strongly correlated $(R=0.95$ and 0.95 , respectively) with the Ångström exponent. The latter has a meaningful variation with respect to the changes in the complex refractive index of the atmospheric aerosols. Furthermore the polarized phase function shows a moderate negative correlation with respect to the atmospheric aerosol optical depth and single-scattering albedo $(R=-0.76$ and -0.33 , respectively). Therefore the polarized phase function can be regarded as a key parameter to characterize the atmospheric particles of the region - a populated city in the semi-arid area and surrounded by some dust sources of the Earth's dust belt.
\end{abstract}

\section{Introduction}

Physical and optical properties of the atmospheric aerosols are from the major uncertainties in the global climate changes (IPCC, 2007). In order to reduce the lack of extensive and reliable information about aerosols and their im- pacts on atmosphere, they have been widely investigated by ground-based measurements and satellite remote sensing suites (Heintzenberg et al., 1997; Kaufman et al., 2002). Ground-based measurements are ideal for reliable and continuous derivation of local aerosol optical and physical properties due to negligible effects of surface background on the measurements, and satellite measurements provide less accurate information about aerosols but in a global coverage (Holben et al., 1998; Dubovik et al., 2002). Satellite remote sensing and ground-based measurements are complementary methods to study aerosols properties and their effects on climate. They have been investigated by using active (e.g., spaceborne and ground-based lidars) (Bösenberg et al., 2003; Winker et al., 2007) and passive (e.g., spaceborne spectrometers and ground-based sun-photometers) instruments (Holben et al., 1998; Prospero et al., 2002; Ginoux et al., 2012).

Iran is located within Earth's so-called dust belt. Many cities in the western, eastern, southern, and central parts of this country have been subjected to dust events of different strengths, especially during the recent years. Previous observations show that the Tigris-Euphrates basin in the west, the Arabian Peninsula in the south and southwest, and the arid region between the Caspian and Aral seas in the north are the main external sources for the observed dust activities in this region (Prospero et al., 2002; Leon and Legrand, 2003; Goudie et al., 2006; Bayat et al., 2011; Abdi et al., 2011, 2012; Sabetghadam et al., 2012; Masoumi et al., 2013). There are also some minor active dust sources inside the 
Iranian Plateau (Abdi et al., 2011, 2012; Masoumi et al., 2013). Zanjan, a city in northwest Iran, is located in a mountainous region at $36.70^{\circ} \mathrm{N}, 48.51^{\circ} \mathrm{E}$, and $1800 \mathrm{~m}$ above the mean sea level (a.m.s.l). Based on the recordings of Zanjan's Meteorological office, the average of sunlight hours for this city is more than $7 \mathrm{~h}$ per day (Samimi et al., 1997). Considering the geographical location as well as the climatological conditions and lack of measured data for the region, groundbased measurements in this city provide valuable information on the dust activities as well as aerosol types and their optical and physical properties.

Aerosol classification using ground-based remote sensing techniques can help to improve the estimation of aerosol radiative impact on climate and the accuracy of satellite retrievals (Dubovik et al., 2002; Cattrall et al., 2005; Giles et al., 2012). Various methods based on aerosol optical and physical properties have been used to classify different types of aerosols from ground-based sun-photometer (SPM) measurements. The extinction of sunlight by aerosols when it passes vertically through the atmosphere from the top of the atmosphere to the surface is called the aerosol optical depth $\left(\tau_{\mathrm{a}}\right)$. This parameter and its spectral dependence with respect to wavelength (i.e., the Ångström exponent, $\alpha$ ) are the commonly used parameters to distinguish the dominant aerosol types (e.g., Toledano et al., 2007; Kalapureddy et al., 2009; Bayat et al., 2011; Boselli et al., 2012; Masoumi et al., 2013). Studies (Gobbi et al., 2007; Basart et al., 2009) have shown that the derivative of $\alpha$ or the spectral difference of $\alpha$-wavelength pairs together with $\tau_{\mathrm{a}}$ and the particle's effective radius can be used to infer different aerosol types. In other works, variations of aerosol single-scattering albedo (the ratio of scattering to extinction coefficients of particles, $\omega_{0}$ ) with respect to their sizes have been used to distinguish aerosol types (Omar et al., 2005; Mielonen et al., 2009; Lee et al., 2010; Russell et al., 2010; Giles et al., 2012). As a result of the mentioned methods, $\tau_{\mathrm{a}}, \alpha, \omega_{0}$, and size distributions retrieved from non-polarized measurements of SPM are commonly used to categorize different types of aerosols, but the polarization ones are mainly neglected.

Polarized sky radiance resulting from interaction between sunlight and atmospheric particles strongly depends on the presence of aerosols in the atmosphere, and can be monitored by looking at the aerosol polarized phase function, $q_{\mathrm{a}}(\Theta)$ (Vermeulen et al., 2000; Li et al., 2004, 2006). The $q_{\mathrm{a}}(\Theta)$ is indicative of the linear polarization of the scattered light that has been generated by the atmospheric aerosols $(\mathrm{Li}$ et al., 2004). Based on the relationship between the polarized sky radiance measured by SPM and its theoretical estimation from applying the Mie scattering theory, $\mathrm{Li}$ et al. (2004) showed that $q_{\mathrm{a}}(\Theta)$ is sensitive to the aerosol size distribution and aerosol complex refractive index. Therefore, $q_{\mathrm{a}}(\Theta)$ has been introduced as another effective and unique aerosol parameter for the accurate retrieval of the aerosols' physical parameters ( $\mathrm{Li}$ et al., 2004, 2006). In this work, both non-polarimetric and polarimetric measurements of a
Cimel CE318-2 SPM at $870 \mathrm{~nm}$ have been used to retrieve $\omega_{0}$ and $q_{\mathrm{a}}(\Theta)$ of the aerosols for the atmosphere of Zanjan. These parameters have been retrieved from recordings of sun-scattered radiance measurements at $870 \mathrm{~nm}$ in the solar principal plane (SPP) mode of the sun-photometer in the period from February 2010 to December 2012. The SPP is a sweep of sky in a plane that includes the sun and the zenith direction. It should be mentioned that $870 \mathrm{~nm}$ has been chosen because it is the only polarized measurement channel on the SPM. Here, we are looking for potentials of the polarized phase function in categorizing of different aerosol types in the atmosphere of Zanjan, a populated city (about 500000 people) (Fathi et al., 2010) in a semi-arid area. To characterize the atmospheric aerosols, we looked at the correlation between $q_{\mathrm{a}}(\Theta)$ and $\alpha$ as well as $q_{\mathrm{a}}(\Theta)$ and $\tau_{\mathrm{a}}$. Also the correlation between $q_{\mathrm{a}}(\Theta)$ and $\omega_{0}$ has been considered.

The rest of the manuscript is organized as follows: in Sect. 2, the instrumentation and recording data are described. The retrieval algorithm of aerosol parameters is explained in Sect. 3. The results obtained are discussed in Sect. 4, and finally the conclusions of this work are presented in Sect. 5.

\section{Instrumentation and data}

In this work, we have investigated the data recorded by a polarized sun-photometer (Cimel CE318-2) from February 2010 to December 2012. The SPM records the sun and sky radiances at five wavelength channels, 440, 675, 870,936 , and $1020 \mathrm{~nm}$, where the $870 \mathrm{~nm}$ channels consist of one non-polarized and three polarized channels to measure the Stokes parameters (Holben et al., 1998). The SPM is installed at the Institute for Advanced Studies in Basic Sciences, IASBS, $\left(36.70^{\circ} \mathrm{N}, 48.51^{\circ} \mathrm{E}\right.$, and $1800 \mathrm{~m}$ a.m.s.l), which from now on we will refer to as the IASBS site. The SPM in the IASBS site has been registered on the AERONET since 5 December 2009, and has been calibrated under the protocols of the network for the mentioned period. It should be added that from 9 October 2010 to 2 March 2011, and 18 January 2012 to 3 August 2012, the SPM was sent for calibration ${ }^{1}$.

We used the sun mode data at 440,675 , and $870 \mathrm{~nm}$ wavelength channels to obtain $\tau_{\mathrm{a}}$ and $\alpha$. Also the SPP sky radiance measurements at $870 \mathrm{~nm}$ were used to retrieve aerosol $\omega_{0}$ and $q_{\mathrm{a}}(\Theta)$. It should be added that the optical absorption of the atmospheric gasses at the polarized channel of the SPM at $870 \mathrm{~nm}$ is almost minimum in comparison to all other wavelength channels of the SPM (Holben et al., 1998; Vermeulen et al., 2000; Li et al., 2006). During the retrieval of the abovementioned parameters, most of the cloud-contaminated data were eliminated using the AERONET cloud-screening algorithm (Smirnov et al., 2000). After applying the screening

\footnotetext{
${ }^{1}$ The calibrations were carried out in the Photon Group, Laboratoire d'Optique Atmosphérique (LOA) - UFR de Physique Université des Sciences et Technologies de Lille (USTL) - CNRS.
} 
algorithm, some contaminations still remained in the data due to the existence of inhomogeneous scattered clouds. These have been identified and removed by fitting a robust locally weighted regression to the radiance measurements in the SPP mode (Li et al., 2004). After applying the above procedure, a total of 305 measurements were left, for which $q_{\mathrm{a}}(\Theta)$ of each them was retrieved, and its potential on classification of the aerosols in Zanjan's atmosphere looked for.

\section{Method}

To investigate the strength of the polarized phase function in categorizing the aerosols in the atmosphere of Zanjan, $\tau_{\mathrm{a}}, \alpha$, $\omega_{0}$, and $q_{\mathrm{a}}(\Theta)$ were retrieved from polarized SPM measurements during a 26-month period, as mentioned in the previous sections. $\tau_{\mathrm{a}}$ and $\alpha$ are two important parameters for the atmospheric aerosols that can be obtained from the sun mode measurements of the SPM. The $\tau_{\mathrm{a}}$ is a measure of the total amount of the atmospheric aerosols and can be derived after subtraction of the molecular optical depth from the total atmospheric optical depth at each wavelength (440, 675, and $870 \mathrm{~nm}$ ) channel (Bodhaine et al., 1999). In retrieving $\tau_{\mathrm{a}}$, the ozone optical depth at $675 \mathrm{~nm}$ and $\mathrm{NO}_{2}$ absorption optical depth at 440 and $675 \mathrm{~nm}$ should be taken into account (Burrows et al., 1999; Boersma et al., 2004). $\alpha$ was retrieved from a linear fit to variations of $\log \tau_{\mathrm{a}}$ with respect to the $\log$ arithm of the wavelength at 440,675 , and $870 \mathrm{~nm}$. The leastsquares method has been applied to find the best fit over data. It should be added that the coefficient of determination, $R^{2}$, for the linear fit was greater than 0.95 in more than $93 \%$ of the measurements.

$\omega_{0}$ and $q_{\mathrm{a}}(\Theta)$ can be respectively retrieved from the unpolarized and polarized sky radiance ( $L$ and $L_{\mathrm{p}}$ ) measurements in the SPP mode at $870 \mathrm{~nm}$ wavelength channels by using the methods introduced by Devaux et al. (1998) and Vermeulen et al. (2000). The propagation of the solar radiation throughout the atmosphere can be modeled by solving the vector radiative transfer equation (VRTE) for a multilayer plane parallel atmosphere, where each layer is specified by its optical depth, single-scattering albedo, and scattering matrix (Chandrasekhar, 1950; Zdunkowski et al., 2007). For randomly oriented particles, in equal number to their mirror particles, the Stokes vector of the scattered light can be obtained by transforming its components for the incident light by means of

$$
\left(\begin{array}{c}
I_{\mathrm{s}} \\
Q_{\mathrm{s}} \\
U_{\mathrm{s}} \\
V_{\mathrm{s}}
\end{array}\right)=\frac{\Omega_{\mathrm{eff}}}{4 \pi}\left(\begin{array}{cccc}
P_{11}(\Theta) & P_{12}(\Theta) & 0 & 0 \\
P_{12}(\Theta) & P_{22}(\Theta) & 0 & 0 \\
0 & 0 & P_{33}(\Theta) & P_{34}(\Theta) \\
0 & 0 & -P_{34}(\Theta) & P_{44}(\Theta)
\end{array}\right)\left(\begin{array}{c}
I_{0} \\
0 \\
0 \\
0
\end{array}\right),
$$

where $\Theta$ is the scattering angle, and $\Omega_{\text {eff }}$ indicates the effective solid angle associated with the scattering angle, and can be obtained by the normalization of the phase function, $p_{\mathrm{a}}(\Theta)$ (i.e., the $P_{11}(\Theta)$ term) (Van de Hulst, 1980; Zdunkowski et al., 2007). Here, the aerosol polarized phase function, $q_{\mathrm{a}}(\Theta)$, stands for the $P_{12}(\Theta)$ term. For spherical particles, $P_{11}(\Theta)=P_{22}(\Theta)$ and $P_{33}(\Theta)=P_{44}(\Theta)$, the Mie scattering theory can be used to calculate different elements of the scattering matrix (Liou, 2002). Also, Dubovik et al. (2006) developed a code to calculate these elements for the shape mixtures of randomly oriented spheroids with the axis ratio ranging from $\sim 0.3$ (flattened spheroids) to $\sim 3.0$ (elongated spheroids) and the size parameter ranging from $\sim 0.012$ to $\sim 625$ (Dubovik et al., 2006). We also compared these two techniques for our measurements to investigate how much the retrieved values of $q_{\mathrm{a}}(\Theta)$ depend on the shape consideration for the aerosols. $I, Q, U$, and $V$ are the Stokes parameters, and the subscript "s" refers to the scattered light. Since the incident solar light at the top of the atmosphere is unpolarized, its Stokes parameters would be represented by $\left[I_{0}, 0,0,0\right]$. At the ground level, $L$ and $L_{\mathrm{p}}$ are respectively equal to $I_{\mathrm{S}}$ and $Q_{\mathrm{s}}$, which can be extracted from the unpolarized and polarized measurements of the SPM at $870 \mathrm{~nm}$ in the SPP mode (Vermeulen et al., 2000; Li et al., 2007, 2009). The total and polarized sky radiance in the SPP measurement mode can be estimated by solving the VRTE and using the successive order of scattering method (Siewert, 1982; Deuzé et al., 1989; Dubovik et al., 2000; Lenoble et al., 2007; Zdunkowski et al., 2007). Table 1 shows the required parameters that should be used in VRTE to estimate the $L$ and $L_{\mathrm{p}}$. Also, the corresponding measurement or retrieval technique for each parameter is presented in Table 1.

Using the obtained $L$ and $L_{\mathrm{p}}$, one may retrieve $\omega_{0}, p_{\mathrm{a}}(\Theta)$, and $q_{\mathrm{a}}(\Theta)$ (Devaux et al., 1998; Vermeulen et al., 2000). For simplicity from now on we remove the argument $\Theta$ and write $p_{\mathrm{a}}(\Theta)$ and $q_{\mathrm{a}}(\Theta)$ as simply $p_{\mathrm{a}}$, and $q_{\mathrm{a}}$. In this method, the contributions of ground reflectance, molecular scattering, and aerosol multiple scattering have been eliminated from the measurements to retrieve the single-scattering properties of the atmospheric aerosols (Vermeulen et al., 2000). Since the ratio (single scattering) / (total scattering) of the sky radiance is nearly the same for measurements and calculations, the relationship between the actual and estimated (marked with a superscript $*$ ) sky radiance is given by

$\frac{\omega_{0}}{\omega_{0}^{*}} p_{\mathrm{a}}=\frac{L-\left(L^{*}-L_{0}^{*}\right)}{L_{0}{ }^{*}} p_{\mathrm{a}}^{*}+\frac{L-L^{*}}{L_{0}{ }^{*}} \frac{\tau_{\mathrm{m}}}{\omega_{0}^{*} \tau_{\mathrm{a}}} p_{\mathrm{m}}$,

where $L$ is the measured and $L^{*}$ the estimated total sky radiance. $L_{0}^{*}, p_{\mathrm{a}}^{*}, p_{\mathrm{m}}$, and $\tau_{\mathrm{m}}$ are the estimated sky radiance in the absence of ground reflection, the estimated aerosol phase function, the molecular phase function, and the molecular optical depth, respectively (Vermeulen et al., 2000). Considering the normalization condition for $p_{\mathrm{a}}$, i.e.,

$$
\int_{0}^{\pi} \omega_{0} p_{\mathrm{a}} \sin \Theta \mathrm{d} \Theta=2 \omega_{0},
$$


Table 1. The required parameters for solving VRTE to calculate the $L$ and $L_{\mathrm{p}}$..

\begin{tabular}{lll}
\hline Parameter & Measurement or retrieval technique & Reference \\
\hline$\tau_{\mathrm{a}}(870 \mathrm{~nm})$ & Sun mode recordings & Holben et al. (1998) \\
\hline$\alpha$ & Retrieved from $\tau_{\mathrm{a}}$ at 440, 675, 870 nm & Toledano et al. (2007) \\
\hline \multirow{2}{*}{$\tau_{\mathrm{m}}$} & $\begin{array}{l}\text { Surface pressure recorded data } \\
\text { from on site weather station } \\
(\text { CIMEL, model: ENERCO 408p) }\end{array}$ & Bodhaine et al. (1999) \\
\hline Solar zenith angle & Astronomical Almanac's algorithm & Michalsky (1988) \\
\hline Ground surface reflectance & MODIS surface reflectance product & Lucht et al. (2000) \\
\hline Molecular scattering matrix & Rayleigh scattering theory & Liou (2002) \\
\hline Aerosol scattering matrix & $\begin{array}{l}\text { Spherical model } \\
\text { Spheroid model }\end{array}$ & $\begin{array}{l}\text { Liou (2002) } \\
\text { Dubovik et al. (2006) }\end{array}$ \\
\hline$\omega_{0}$ & $\begin{array}{l}\text { Spherical model } \\
\text { Spheroid model }\end{array}$ & $\begin{array}{l}\text { Liou (2002) } \\
\text { Dubovik et al. (2006) }\end{array}$ \\
\hline
\end{tabular}

and Eq. (2) will lead to

$\frac{2 \omega_{0}}{\omega_{0}^{*}}=\int_{0}^{\pi}\left(\frac{L-\left(L^{*}-L_{0}^{*}\right)}{L_{0}^{*}} p_{\mathrm{a}}^{*}+\frac{L-L^{*}}{L_{0}^{*}} \frac{\tau_{\mathrm{m}}}{\omega_{0}^{*} \tau_{\mathrm{a}}} p_{\mathrm{m}}\right) \sin \Theta \mathrm{d} \Theta$

where $\Theta$ is the scattering angle. The right-hand side of Eq. (4) has been calculated for $\omega_{0}^{*}=0.6,0.7,0.8,0.9$, and 1.0, and then an interpolation has been applied to the obtained values to converge the value of the integral to 2 , which would lead to $\omega_{0}^{*}=\omega_{0}$ on the left-hand side. Replacing the retrieved value of $\omega_{0}$ in Eq. (2), the measured aerosol phase function can be retrieved as

$p_{\mathrm{a}}=\frac{L-\left(L^{*}\left(\omega_{0}\right)-L_{0}^{*}\left(\omega_{0}\right)\right)}{L_{0}^{*}\left(\omega_{0}\right)} p_{\mathrm{a}}^{*}+\frac{L-L^{*}\left(\omega_{0}\right)}{L_{0}^{*}\left(\omega_{0}\right)} \frac{\tau_{\mathrm{m}}}{\omega_{0} \tau_{\mathrm{a}}} p_{\mathrm{m}}$.

In the same way $q_{\mathrm{a}}$ can be written as

$q_{\mathrm{a}}=\frac{L_{\mathrm{p}}}{L_{\mathrm{p}}^{*}\left(\omega_{0}\right)} q_{\mathrm{a}}^{*}+\frac{L_{\mathrm{p}}-L_{\mathrm{p}}^{*}\left(\omega_{0}\right)}{L_{\mathrm{p}}^{*}\left(\omega_{0}\right)} \frac{\tau_{\mathrm{m}}}{\omega_{0} \tau_{\mathrm{a}}} q_{\mathrm{m}}$,

where $q_{\mathrm{a}}^{*}$ is the estimated polarized phase function and $q_{\mathrm{m}}$ is the molecular polarized phase function (Vermeulen et al., 2000). It has already been shown that for a calibrated Cimel SPM, the uncertainty in $\tau_{\mathrm{a}}(870 \mathrm{~nm})$ is \pm 0.01 , and the estimated total error of the retrieved $\omega_{0}$ at $870 \mathrm{~nm}$ is about \pm 0.05 . The uncertainty of $q_{\mathrm{a}}$ at $870 \mathrm{~nm}$ when $20^{\circ}<\Theta<$ $120^{\circ}$ is about $10 \%$ (Holben et al., 1998; Devaux et al., 1998; Vermeulen et al., 2000; Li et al., 2006).

\section{Results and discussions}

The algorithm that has been used to retrieve the aerosol optical properties is not sensitive to the particle shape assumptions ( $\mathrm{Li}$ et al., 2006). Figure 1 is a comparison between the retrieved values of $q_{\mathrm{a}}(\max )$ for the mentioned measured data set in the IASBS site with two different assumptions on the shape of the aerosols, spheres (blue empty squares), and spheroids (black solid circles). The Mie scattering theory has been used to calculate $q_{\mathrm{a}}(\max )$ for spherical particles by considering a bimodal log-normal size distribution with 22 bins, with radii ranging from 0.05 to $15 \mu \mathrm{m}$, and the code that was introduced by Dubovik et al. (2006) has been implemented to retrieve the $q_{\mathrm{a}}$ ( $\max$ ) values for the shape mixtures of the randomly oriented polydisperse spheroid model. For spheroid particles, the calculations have been made for 25 bins of the spheroid axis ratio ranging from $\sim 0.3$ (flattened spheroids) to $\sim 3.0$ (elongated spheroids) and for 22 narrow size bins covering the radii from 0.05 to $15 \mu \mathrm{m}$. Figure 1 shows that the calculated results are almost insensitive to the assumed shapes for the particles. The maximum difference between the two models' retrieved values for $q_{\mathrm{a}}(\max )$ is about 0.030 , which is of the order of the resolution of the retrieval procedure. From now on for the rest of this manuscript, the atmospheric particles have been considered as distributed spheres of different sizes as mentioned before.

Figure 2 shows the correlation between the retrieved values of $\omega_{0}$ for the IASBS site obtained from the SPP mode measurements and AERONET results that have been retrieved from the almucantar sky recordings at $870 \mathrm{~nm}$. The retrieved $\omega_{0}$ accuracy from both mentioned algorithms depends on $\tau_{\mathrm{a}}$; that is, the larger the $\tau_{\mathrm{a}}$, the better the accuracy (Devaux et al., 1998; Dubovik et al., 2002). The difference between the results obtained from the two mentioned techniques is less than 0.05 for most of the cases. Furthermore, the differences can be due to the time difference of about 10 min between these two measurement modes as well as to the different impact of the surface reflectance on their measurement geometries. 


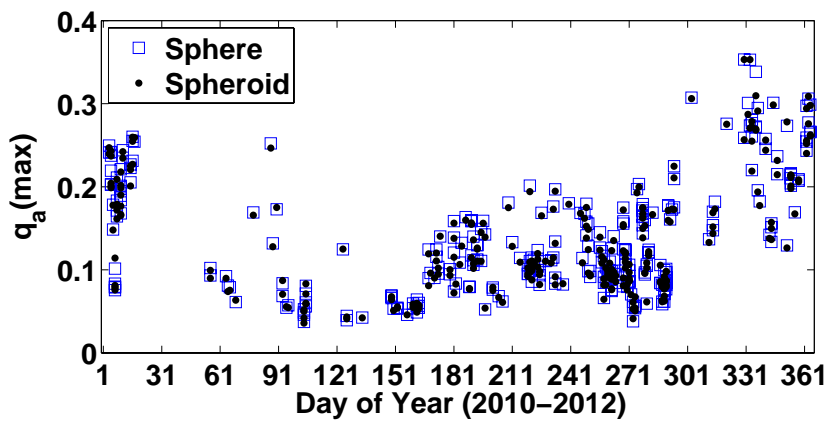

Fig. 1. Comparison between the maximum values of the retrieved aerosol polarized phase function, $q_{\mathrm{a}}(\max )$, for two assumptions on the shape of the particles, spheres (blue empty squares), and spheroids (black solid circles).

Aerosol properties including $\tau_{\mathrm{a}}$ at $870 \mathrm{~nm}, \alpha$ (retrieved from $\tau_{\mathrm{a}}$ at 440,675 , and $\left.870 \mathrm{~nm}\right), \omega_{0}$ at $870 \mathrm{~nm}$, and $q_{\mathrm{a}}$ at $870 \mathrm{~nm}$ as well as their correlations have been studied in this work to investigate how the polarized phase function can be used to characterize the atmospheric aerosols in the atmosphere of Zanjan. Temporal variations of the $\tau_{\mathrm{a}}, \alpha, q_{\mathrm{a}}$, and $\omega_{0}$ values appear in Fig. 3a-d for the measurement period mentioned in Sect. 2. $\tau_{\mathrm{a}}$ reaches its maximum value $(\sim 0.60)$ by the end of spring, and its lowest value almost in late autumn (Fig. 3a). The Ångström exponent in Fig. 3b also shows an almost seasonal periodic variation during the year. In May and June, it reaches its lowest values $(\sim 0.07)$ as an indication of the existence of large atmospheric particles, and its highest values are reached in late autumn and early winter. The maximum value of the polarized phase function, $q_{\mathrm{a}}(\max )$ in Fig. $3 \mathrm{c}$ shows a behavior quite similar to that of $\alpha$. Figure $3 \mathrm{~d}$ is somehow close to the mirror image of Fig. 3b and $\mathrm{c}$ with respect to the time axis. In other words, particles with higher values of $\omega_{0}$ (up to 0.99) mostly appear in late spring and summer, but in autumn and winter, the atmosphere is mostly contaminated with particles with lower values of $\omega_{0}$ (down to 0.90 ).

It should be noted that the city of Zanjan is located in a semi-arid area, away from grasslands and forests as sources of biomass burning aerosols as well as from seas as origins of marine aerosols. Hence we do not expect to observe biomass burning and marine aerosols in the region. Therefore, in agreement with our previous works (Bayat et al., 2011; Abdi et al., 2011, 2012; Masoumi et al., 2013) urban/industrial and desert dust aerosols are the main particles in the atmosphere of Zanjan. Looking back at Fig. 3, one can conclude that increases in the average size of the aerosols decrease their optical absorption. This can be related to the excess of dust loading into the atmosphere, especially in spring and summer times. Also an increase in $\alpha$ and a decrease in $\omega_{0}$ in autumn and winter indicate the existence of urban/industrial aerosols as the dominant atmospheric particles. However, a mixture of the above-mentioned two types of aerosols are present in

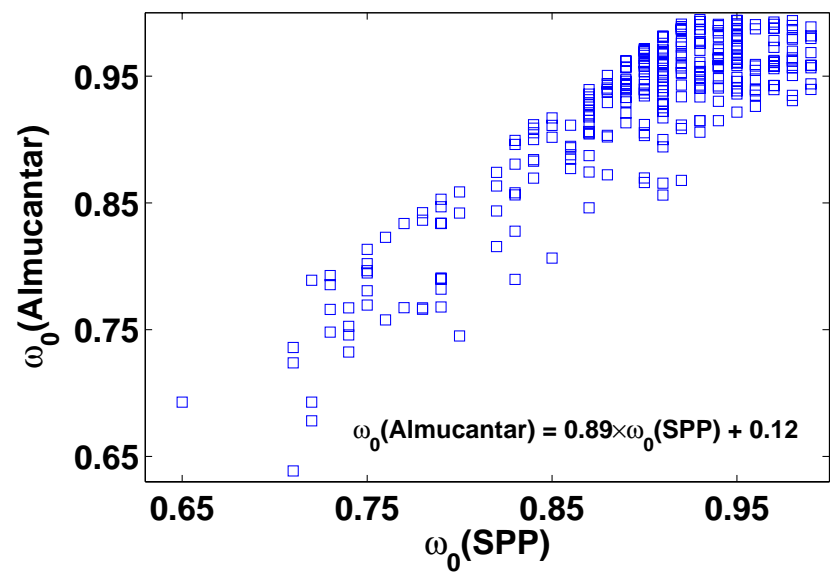

Fig. 2. $\omega_{0}$ values retrieved from measurements in almucantar (AERONET) mode versus $\omega_{0}$ extracted from SPP measurements (our technique), IASBS site, February 2010 to December 2012.

the atmosphere throughout the year. Therefore, the particulate matter that may be loaded into the atmosphere of this area can be categorized into three regimes: the first, dominant urban/industrial aerosols $(\alpha>1.2)$; the second, dominant desert dust $(\alpha<0.6)$, especially due to the transfer of dust from the Tigris-Euphrates basin (Bayat et al., 2011; Abdi et al., 2011, 2012; Masoumi et al., 2013); and the last one, a mixture of urban/industrial and dust aerosols (0.6 $\leq \alpha \leq 1.2$ ). These three categories are presented in Table 2 . Table 2 indicates the minimum, maximum, and mean values of $\tau_{\mathrm{a}}, \alpha, \omega_{0}$, and $q_{\mathrm{a}}(\max )$ for each category as well as their absolute and relative (in percent) occurrence for a total of 305 measurements from February 2010 to December 2012 at the IASBS site. Even though different aerosol types can be classified using $\tau_{\mathrm{a}}$ and $\alpha$ (Table 2); however, referring to columns $10-12$ of Table 2 , one can see that $q_{\mathrm{a}}(\max )$ also well categorizes the above-mentioned aerosol types.

Figure 4 depicts variations of $q_{\mathrm{a}}$ versus the scattering angle for two measurements with the same $\tau_{\mathrm{a}}$ but different $\alpha$. The larger (smaller) $\alpha=1.49(\alpha=0.78)$ corresponds to the larger (smaller) value of $q_{\mathrm{a}}(\max )=0.22\left(q_{\mathrm{a}}(\max )=0.09\right)$. Figure 4 is an example of such comparisons, and other measurements also show similar behavior. To have a better understanding of this behavior, the maximum values of $q_{\mathrm{a}}$ are plotted against $\alpha$ in Fig. 5, and a robust linear fit has been applied to them. As can be seen from Fig. 5, a positive correlation (correlation coefficient $R=0.95$ ) exists between these parameters. The color bar in Fig. 5 corresponds to $\tau_{\mathrm{a}}$ values on the logarithmic scale. Also, the figure shows that as $\tau_{\mathrm{a}}$ increases, the average size of the atmospheric aerosols also increases, but $q_{\mathrm{a}}(\max )$ has a decreasing trend.

In Fig. 6, variations of $q_{\mathrm{a}}$ at different scattering angles have been compared for atmospheres with the same $\alpha$ but different $\tau_{\mathrm{a}}$. These results illustrate a moderate influence of the variations of $\tau_{\mathrm{a}}$ on $q_{\mathrm{a}}$. Figure 7 depicts the variations of 
Table 2. Minimum (min), maximum (max), and mean values of $\tau_{\mathrm{a}}, \alpha, \omega_{0}$, and $q_{\mathrm{a}}(\max )$ for 305 selected measurements in each dominant category of aerosols in Zanjan's atmosphere, February 2010 to December 2012, IASBS site.

\begin{tabular}{|c|c|c|c|c|c|c|c|c|c|c|c|c|c|c|}
\hline & \multicolumn{3}{|c|}{$\tau_{\mathrm{a}}$} & \multicolumn{3}{|c|}{$\alpha$} & \multicolumn{3}{|c|}{$\omega_{0}$} & \multicolumn{3}{|c|}{$q_{\mathrm{a}}(\max )$} & \multicolumn{2}{|c|}{ Occurrence number } \\
\hline & $\min$ & $\max$ & mean & $\min$ & $\max$ & mean & $\min$ & $\max$ & mean & $\min$ & $\max$ & mean & Absolute & Relative (\%) \\
\hline Urban industrial $(\alpha>1.2)$ & 0.02 & 0.17 & 0.06 & 1.21 & 1.79 & 1.43 & 0.71 & 0.99 & 0.86 & 0.13 & 0.35 & 0.23 & 81 & 27 \\
\hline Desert dust $(\alpha<0.6)$ & 0.06 & 0.59 & 0.24 & 0.07 & 0.60 & 0.39 & 0.71 & 0.99 & 0.90 & 0.04 & 0.10 & 0.07 & 71 & 23 \\
\hline Mixed $(0.6 \leq \alpha \leq 1.2)$ & 0.06 & 0.28 & 0.13 & 0.60 & 1.18 & 0.84 & 0.66 & 0.99 & 0.91 & 0.06 & 0.21 & 0.12 & 153 & 50 \\
\hline Total & 0.02 & 0.59 & 0.14 & 0.07 & 1.79 & 0.89 & 0.66 & 0.99 & 0.90 & 0.04 & 0.35 & 0.14 & 305 & 100 \\
\hline
\end{tabular}

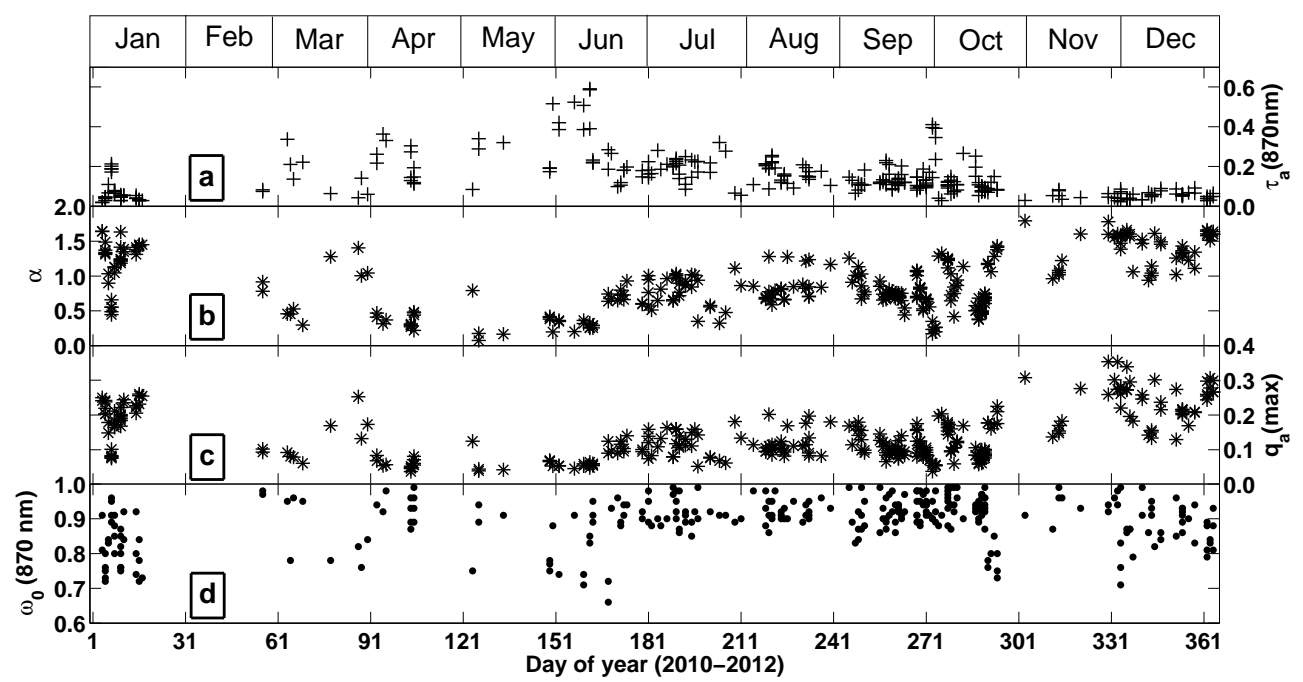

Fig. 3. (a) $\tau_{\mathrm{a}}(870 \mathrm{~nm}),(\mathbf{b}) \alpha$, (c) $q_{\mathrm{a}}(\max )$, and (d) $\omega_{0}$ retrieved values versus day of year, February 2010 to December 2012 , IASBS site.

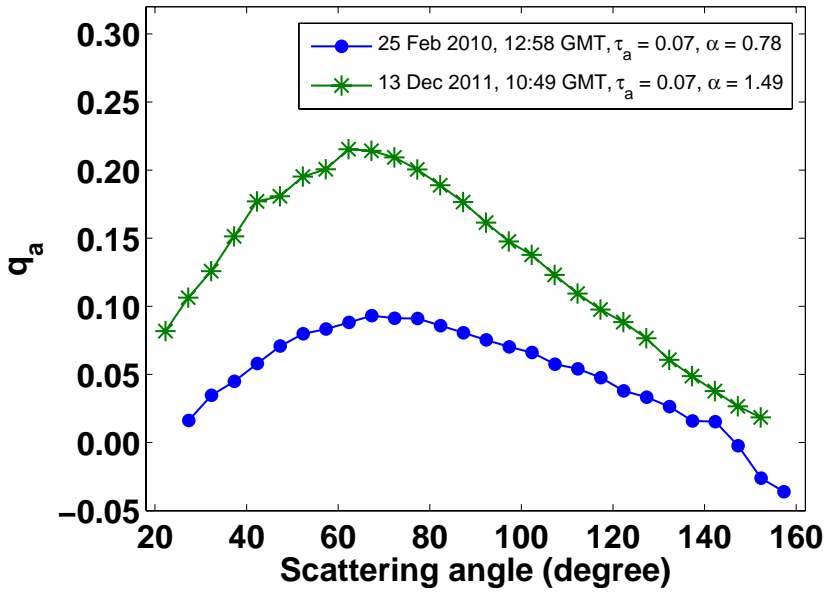

Fig. 4. Retrieved $q_{\mathrm{a}}$ at $870 \mathrm{~nm}$ versus the scattering angle in the atmosphere of Zanjan for two measurements with same $\tau_{\mathrm{a}}$ and different $\alpha$, IASBS site.

$q_{\mathrm{a}}(\max )$ at different values of $\tau_{\mathrm{a}}$. Colors in this figure are mapped to different values of $\alpha$ on a linear scale. By looking at Fig. 7 , one can conclude that $q_{\mathrm{a}}(\max )$ has a linear negative correlation (correlation coefficient $R=-0.76$ ) with $\tau_{\mathrm{a}}$ on the logarithmic scale. The results of Fig. 7 are in agreement

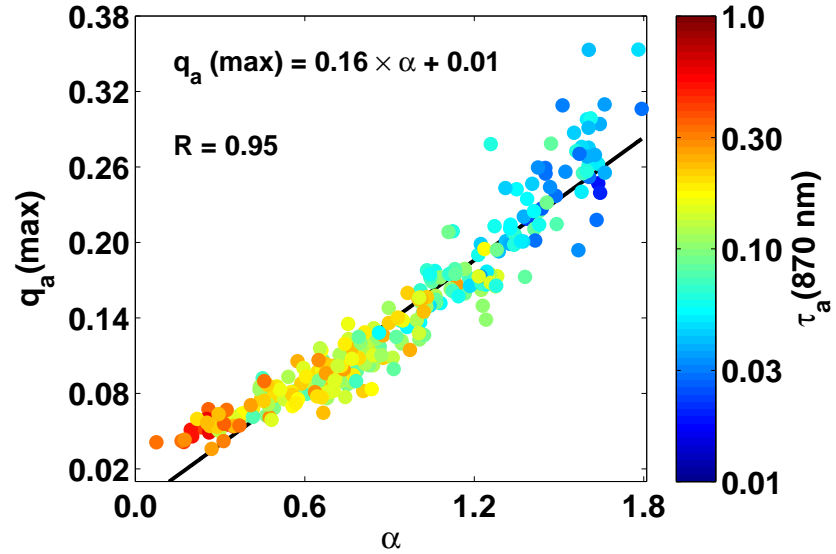

Fig. 5. Strong positive correlation between $q_{\mathrm{a}}(\max )$ at $870 \mathrm{~nm}$ and $\alpha$. Colors are mapped to $\tau_{\mathrm{a}}$ on the logarithmic scale, February 2010 to December 2012, IASBS site.

with Fig. 5. It may be concluded that when the atmosphere in Zanjan area has lower $\tau_{\mathrm{a}}$ values (lower aerosol loading), it is mostly contaminated with fine-mode particles that are mostly urban/industrial particles.

Aerosol single-scattering albedo is another crucial parameter to characterize the atmospheric aerosols. It mostly 


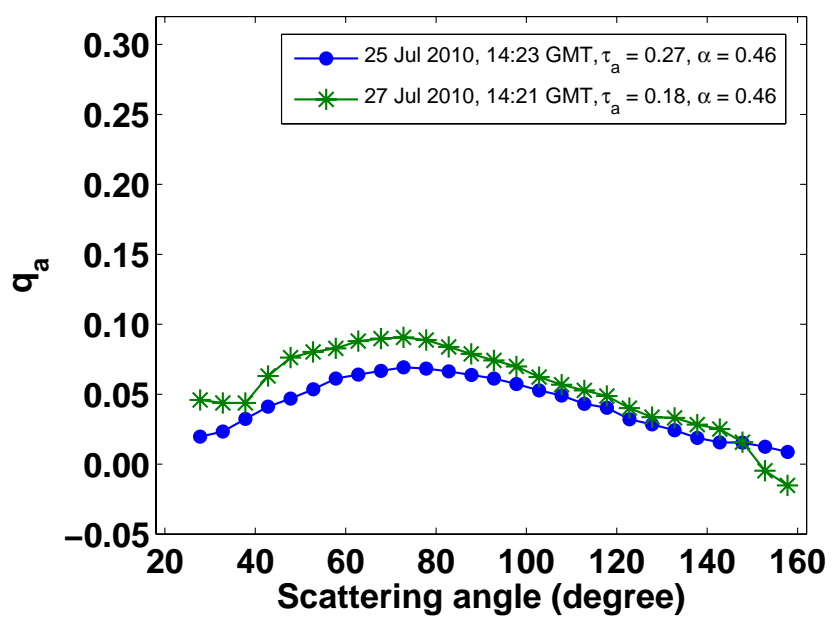

Fig. 6. Retrieved $q_{\mathrm{a}}$ at $870 \mathrm{~nm}$ versus the scattering angle in the atmosphere of Zanjan for two measurements with same $\alpha$ and different $\tau_{\mathrm{a}}$, IASBS site.

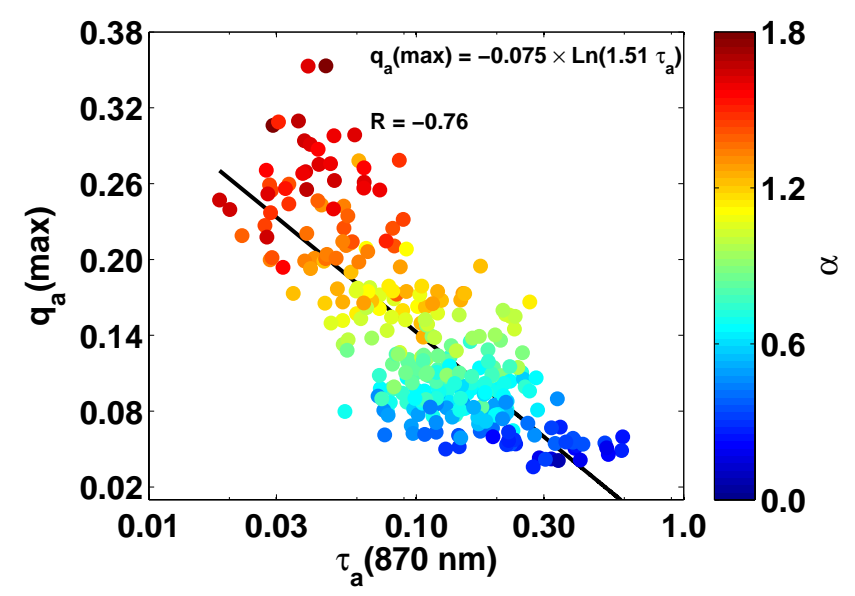

Fig. 7. Variations of $q_{\mathrm{a}}(\max )$ versus $\tau_{\mathrm{a}}(870 \mathrm{~nm})$ on the logarithmic scale. Colors are mapped to $\alpha$ in linear scale, February 2010 to December 2012, IASBS site.

depends on the particle composition and size distribution (Dubovik et al., 2002). Figure 8 shows the correlation between $q_{\mathrm{a}}(\max )$ and $\omega_{0}$, where colors indicate the variations of $\tau_{\mathrm{a}}$ on the logarithmic scale. Also, each data point has been specified by a solid circle whose diameter is mapped to $\alpha^{-1}$ as a qualitative measure of the particle size. For $\tau_{\mathrm{a}}>0.30$, $q_{\mathrm{a}}(\max )$ is almost constant $(\sim 0.05)$, and it is not sensitive to $\omega_{0}$ variations. Also, a moderate negative correlation between $q_{\mathrm{a}}(\max )$ and $\omega_{0}$ can be observed, when $\tau_{\mathrm{a}}$ is less than 0.30 . As a result, the existence of smaller and absorptive aerosols that are commonly associated with lower amounts of aerosol loading leads to larger values of the polarized phase function. Referring to Figs. 5, 7, and 8 and Table 2, one can conclude that $q_{\mathrm{a}}(\max )$ can be chosen as a good candidate to classify different types of aerosols in the atmosphere of Zanjan. This can be seen from the mean values of $q_{\mathrm{a}}(\max )$ in three se-

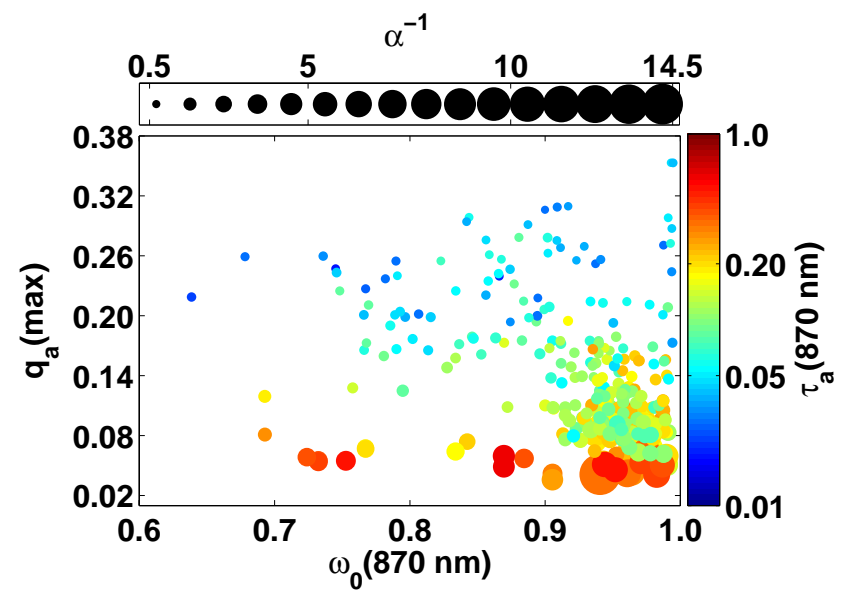

Fig. 8. Correlation between $q_{\mathrm{a}}(\max )$ and $\omega_{0}$ at $870 \mathrm{~nm}$. Colors are mapped to different values of $\tau_{\mathrm{a}}$. The diameter of each data point corresponds to $\alpha^{-1}$.

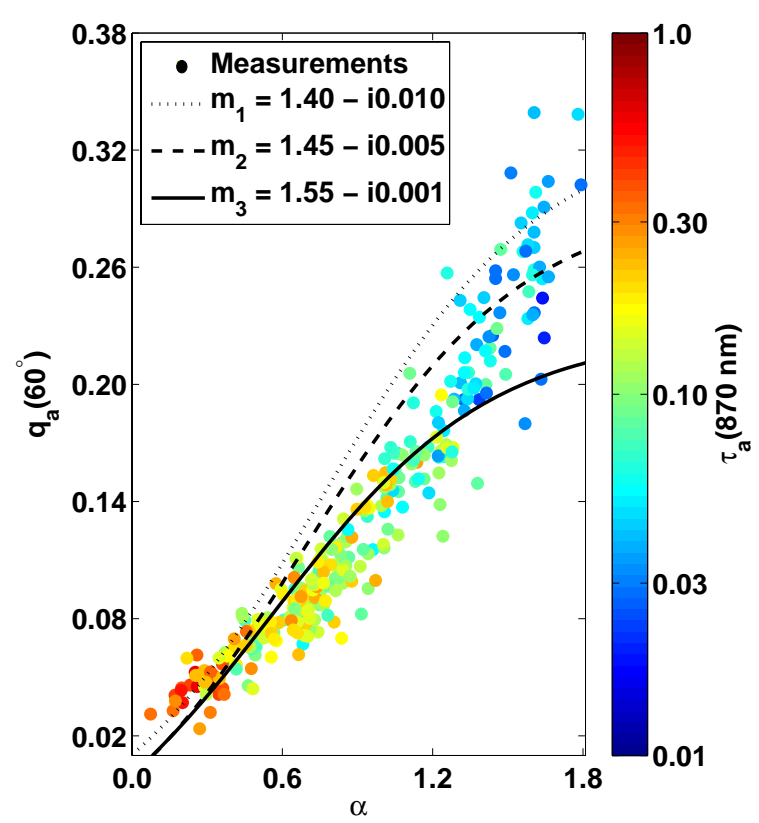

Fig. 9. $q_{\mathrm{a}}\left(60^{\circ}\right)$ versus $\alpha$ for 305 retrieved data points (colored circles). Lines are calculated for three different assumed refractive indices based on the Mie scattering theory.

lected categories of Table 2, where its corresponding values are $0.23,0.07$, and 0.12 , related to an atmosphere with dominant anthropogenic, dominant dust, and combinations of both anthropogenic and dust aerosols, respectively. As a result, the $q_{\mathrm{a}}(\max )$ itself can be used to characterize urban/industrial and desert dust aerosols as two dominant aerosol types in the atmosphere of the cities that are located in arid/semi-arid areas. It should also be noted that $q_{\mathrm{a}}$ is frequently used as a key parameter to obtain more accuracy in the retrieval of other important aerosol properties ( $\mathrm{Li}$ et al., 2006; Dubovik et al., 2006). 


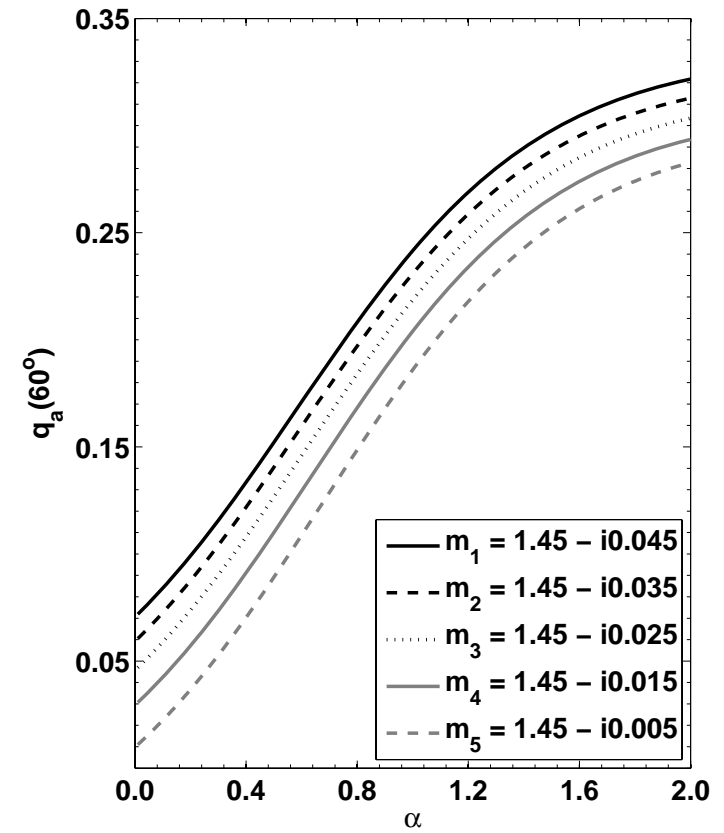

Fig. 10. Calculated $q_{\mathrm{a}}\left(60^{\circ}\right)$ versus $\alpha$, for five different complex refractive indices with the same real part but different imaginary parts based on the Mie scattering theory.

Figure 9 gives more information about the atmospheric aerosol characterization using the polarized phase function. In this figure the variations of the polarized phase function at a scattering angle of $60^{\circ}, q_{\mathrm{a}}\left(60^{\circ}\right)$, versus $\alpha$ has been plotted for three different refractive indices $\left(\mathrm{m}_{1}=1.40-\right.$ $i 0.010, \mathrm{~m}_{2}=1.45-i 0.005$, and $\left.\mathrm{m}_{3}=1.55-i 0.001\right)$ based on the Mie scattering theory. The plots have been overlaid on the retrieved values $q_{\mathrm{a}}\left(60^{\circ}\right)$ for the measurements in the IASBS site. The chosen refractive indices $\mathrm{m}_{1}, \mathrm{~m}_{2}$, and $\mathrm{m}_{3}$ almost correspond with anthropogenic (Dubovik et al., 2002), Southeast Asian (AERONET network, Chen-Kung site in Taiwan), and dust aerosols (Dubovik et al., 2002), respectively. Figure 9 shows that the events with $0.6 \leq \alpha \leq 1.2$ are almost close to the curve corresponding to $m_{3}$ (dust), but as $\alpha$ increases, the retrieved data points get close to the $\mathrm{m}_{2}$ and $\mathrm{m}_{1}$ curves that correspond to the aerosols resulting from incomplete burning of fuel and urban/industrial activities. To confirm this behavior, the root-mean-square distance, RMSD, of the retrieved data points from each curve $\left(\mathrm{m}_{1}, \mathrm{~m}_{2}\right.$, and $m_{3}$ ) has been calculated for the mentioned spans of $\alpha$. Table 3 shows the results obtained. For $\alpha<0.6$, the curves in Fig. 9 cannot distinguish between different aerosol types. This is in agreement with the results obtained by Dubovik et al. (2006) on the behavior of the degree of linear polarization, $-\mathrm{P}_{12} / \mathrm{P}_{11}$, for different aerosol sizes. They also found that $-\mathrm{P}_{12} / \mathrm{P}_{11}$ cannot categorize the coarse-mode particles. Figure 10 shows the calculated values of $q_{\mathrm{a}}\left(60^{\circ}\right)$ for different relative sizes $(\alpha)$ of aerosols and five complex refractive indices with a fixed value for the real part of the re-
Table 3. Root-mean-square distances of retrieved $q_{\mathrm{a}}\left(60^{\circ}\right)$ values from the curves corresponding to $\mathrm{m}_{1}, \mathrm{~m}_{2}$, and $\mathrm{m}_{3}$ refractive indices (Fig. 9) for three different spans of $\alpha$.

\begin{tabular}{lccc}
\hline & $\alpha<0.6$ & $0.6 \leq \alpha \leq 1.2$ & $\alpha>1.2$ \\
\hline $\mathrm{m}_{1}=1.40-i 0.010$ & 0.013 & 0.041 & 0.046 \\
$\mathrm{~m}_{2}=1.45-i 0.005$ & 0.016 & 0.029 & 0.035 \\
$\mathrm{~m}_{3}=1.55-i 0.001$ & 0.017 & 0.015 & 0.055 \\
\hline
\end{tabular}

fractive index and various imaginary parts of the refractive index, based on the Mie scattering theory. The figure shows that increasing the imaginary part of the aerosol refractive indices leads to increased $q_{\mathrm{a}}\left(60^{\circ}\right)$ values for all aerosol relative sizes. As a result of the figure, one can conclude that the larger and non-absorptive aerosols cause the lower polarized phase function and vice versa. In other words the polarized phase function has the potential to distinguish absorbing particles like soot or black carbon from particles like dust or marine aerosols; however this needs more investigation (Li et al., 2004; Dubovik et al., 2006). Finally, looking at Figs. 5, 7, 8, 9, and 10, we conclude that as a powerful aerosol parameter, the polarized phase function can be used to classify different aerosol categories in Zanjan's atmosphere as a populated city located in the central part of the Earth's dust belt.

\section{Conclusions}

In this work, the potential of the polarized phase function in the classification of the atmospheric aerosols for the Zanjan area has been investigated. In doing this, the sun-photometer measurements of the IASBS site from February 2010 to December 2012 have been used to retrieve the aerosol optical depth, Ångström exponent, single-scattering albedo, and the polarized phase function. In retrieving $q_{\mathrm{a}}$ from the sky radiance measurements in the SPP mode, the aerosols have been considered as polydisperse spherical particles. Calculations of the $q_{\mathrm{a}}$ values for shape mixtures of randomly oriented spheroids did not lead to a significant difference from the results of the Mie scattering theory for spherical particles (Fig. 1). In this study, three different conditions have been considered for the existence of the particulate matters in the atmosphere, based on the variations of the Ångström exponent. These include the contamination of the atmosphere either mostly with dust or for clean atmosphere mostly with urban/industrial aerosols, and for the rest of the times a mixture of dust and urban/industrial particles (Table 2). The extremes as well as the mean values of $\tau_{\mathrm{a}}, \alpha, \omega_{0}$, and $q_{\mathrm{a}}$ (max) for these three spans are shown in Table 2. Referring to the $q_{\mathrm{a}}(\max )$ values in Table 2 ( $\mathrm{min}$, max, and mean) for the mentioned three spans suggests $q_{\mathrm{a}}$ as a proper candidate to categorize the different types of aerosols in Zanjan's atmosphere. To prove this, the correlations between $q_{\mathrm{a}}$ and $\alpha, \tau_{\mathrm{a}}$, and $\omega_{0}$ have 
been considered (Figs. 5, 7, and 8). The polarized phase function is strongly correlated $(R=0.95)$ with the Angström exponent, and it has a negative correlation $(R=-0.76)$ with $\tau_{\mathrm{a}}$. The observed correlations indicate that an increase in the $q_{\mathrm{a}}$ values is associated with the existence of fine-mode particles (anthropogenic) and during dust events, when $\tau_{\mathrm{a}}$ increases considerably, the polarized phase function has a decreasing trend. Therefore the type of the existing aerosols in Zanjan's atmosphere can be specified by looking at the variations of the maximum values of the polarized phase function. Depending on the atmospheric conditions, $q_{\mathrm{a}}$ (max) usually occurs at $50-70^{\circ}$ scattering angles. Therefore to check whether $q_{\mathrm{a}}$ is sensitive to the particle type, the retrieved $q_{\mathrm{a}}\left(60^{\circ}\right)$ values were overlaid on the variations of the theoretical $q_{\mathrm{a}}\left(60^{\circ}\right)$ versus $\alpha$ for three different refractive indices corresponding to dust as well as Southeast Asian and urban/industrial aerosols. The results (Fig. 9) show that for the conditions with $\alpha>0.6, q_{\mathrm{a}}\left(60^{\circ}\right)$ can distinguish between these three types of aerosols. Analytical analysis in Fig. 10 also shows how $q_{\mathrm{a}}\left(60^{\circ}\right)$ is sensitive to the imaginary part of the refractive index. In other words, the existence of more absorbing particles like soot or black carbon should increase the $q_{\mathrm{a}}$ value, but this variation still needs more investigation. Thus, as also suggested by Li et al. $(2004,2006)$ and Dubovik et al. (2006), we believe investigating the polarized phase function provides valuable information about the concentration, size, and type of the atmospheric aerosols.

Acknowledgements. The authors would like to express their gratitude to the AERONET team for preparing the almucantar measurement parameters in the network. They are also grateful to Yousef Ali Abedini for valuable discussions and comments on the manuscript and Bahman Farnudi for editing the text.

Edited by: V. Rizi

\section{References}

Abdi, F., Flamant, C., Cuesta, J., Flamant, P., and Khalesifard, H. R.: Multiplatform observations of dust vertical distribution during transport over northwest Iran in the summertime, J. Geophys. Res., 116, D05206, doi:10.1029/2010JD014573, 2011.

Abdi, F., Flamant, C., Cuesta, J., Oolman, L., Flamant, P., and Khalesifard, H. R.: Dust transport over Iraq and northwest Iran associated with winter Shamal: a case study, J. Geophys. Res., 117, D03201, doi:10.1029/2011JD016339, 2012.

Basart, S., Pérez, C., Cuevas, E., Baldasano, J. M., and Gobbi, G. P.: Aerosol characterization in Northern Africa, Northeastern Atlantic, Mediterranean Basin and Middle East from direct-sun AERONET observations, Atmos. Chem. Phys., 9, 8265-8282, doi:10.5194/acp-9-8265, 2009.

Bayat, A., Masoumi, A., and Khalesifard, H. R.: Retrieval of atmospheric optical parameters from ground-based sun-photometer measurements for Zanjan, Iran, Atmos. Meas. Tech., 4, 857-863, doi:10.5194/amt-4-857-2011, 2011.
Bodhaine, B. A., Wood, N. B., Dutton, E. G., and Slusser, J. R.: On Rayleigh optical depth calculations, J. Atmos. Ocean. Tech., 16, 1854-1861, 1999.

Boersma, K. F., Eskes, H. J., and Brinksma, E. J.: Error Analysis for Tropospheric NO2 Retrieval from Space, J. Geophys. Res., 109, D04311, doi:10.1029/2003JD003962, 2004.

Boselli, A., Caggiano, R., Cornacchia, C., Madonna, F., Mona, L., Macchiato, M., Pappalardo, G., and Trippetta, S.: Multi year Sun photometer measurements for aerosol characterization in a Central Mediterranean site, Atmos. Res., 104-105, 98-110, doi:10.1016/j.atmosres.2011.08.002, 2012.

Bösenberg, J. and Matthias, V.: EARLINET: a European aerosol research lidar network to establish an aerosol climatology, MPIReport 348, Hamburg, Germany, 2003.

Burrows , J. P., Richter, A., Dehn, A., Deters, B., Himmelmann, S., Voigt, S., and Orphal, J.: Atmospheric remote-sensing reference data from GOME-2. Temperature-dependent absorption cross sections of $\mathrm{O}_{3}$ in the 231-794 nm range, J. Quant. Spectrosc. Ra., 61, 509-517, 1999.

Cattrall, C., Reagan, J., Thome, K., and Dubovik, O.: Variability of aerosol and spectral lidar and backscatter and extinction ratios of key aerosol types derived from selected Aerosol Robotic Network locations, J. Geophys. Res., 110, D10S11, doi:10.1029/2004JD005124, 2005.

Chandrasekhar, S.: Radiative Transfer, Oxford University Press, Oxford, 1950.

Deuzé, J. L., Herman, M., and Santer, R.: Fourier series expansion of the transfer equation in the atmosphere-ocean system, J. Quant. Spectrosc. Ra., 41, 483-494, 1989.

Devaux, C., Vermeulen A., Deuzé, J. L., Dubuisson, P., Herman, M., Santer, R., and Verbrugghe, M.: Retrieval of aerosol single scattering albedo from ground-based measurements: application to observational data, J. Geophys. Res., 103, 8753-8761, 1998.

Dubovik, O. and King, M. D.: A flexible inversion algorithm for retrieval of aerosol optical properties from sun and sky radiance measurements, J. Geophys. Res., 105, 20673-20696, doi:10.1029/2000JD900282, 2000.

Dubovik, O., Holben, B. N., Eck, T. F., Smirnov, A., Kaufman, Y. J., King, M. D., Tanré, D., and Slutsker, I.: Variability of absorption and optical properties of key aerosol types observed in worldwide locations, J. Atmos. Sci., 59, 590-608, 2002.

Dubovik, O., Sinyuk, A., Lapyonok, T., Holben, B. N., Mishchenko, M., Yang, P., Eck, T. F., Volten, H., Muñoz, O., Veihelmann, B., van der Zande, W. J., Leon, J.-F., Sorokin, M., and Slutsker, I.: Application of spheroid models to account for aerosol particle nonsphericity in remote sensing of desert dust, J. Geophys. Res., 111, D11208, doi:10.1029/2005JD006619, 2006.

Fathi, E. and Hosseini, M.: The estimated population of the provinces of Iran, available at: http://www.amar.org.ir/Portals/ 0/Files/abstract/1389/n_baravord_sh89.pdf (last access: 1 July 2013), Deputy Strategic Planning and Control Statistical Center of Iran, 2010.

Giles, D. M., Holben, B. N., Eck, T. F., Sinyuk, A., Smirnov, A., Slutsker, I., Dickerson, R. R., Thompson, A. M., and Schafer, J. S.: An Analysis of AERONET Aerosol Absorption Properties and Classifications Representative of Aerosol Source Regions, J. Geophys. Res., 117, D17203, doi:10.1029/2012JD018127, 2012. 
Ginoux, P. A., Prospero, J. M., Gill, T. E., Hsu, C., and Zhao, M.: Global scale attribution of anthropogenic and natural dust sources and their emission rates based on MODIS Deep Blue aerosol products, Rev. Geophys., 50, 3, doi:10.1029/2012RG000388, 2012.

Gobbi, G. P., Kaufman, Y. J., Koren, I., and Eck, T. F.: Classification of aerosol properties derived from AERONET direct sun data, Atmos. Chem. Phys., 7, 453-458, doi:10.5194/acp-7-453, 2007.

Goudie, A. S. and Middleton, N.: Desert Dust in the Global System, Springer Press, Heidelberg, 2006.

Heintzenberg, J., Charlson, R. J., Clarke, A. D., Liousse, C., Ramaswamy, V., Shine, K. P., Wendisch, M., and Helas, G.: Measurements and modeling of aerosol single scattering albedo: progress, problems and prospects, Beitr. Phys. Atmos., 70, 249263, 1997.

Holben, B. N., Eck, T. F., Slutsker, I., Tanre, D., Buis, J. P., Setzer, A., Vermote, E., Reagan, J. A., Kaufman, Y. J., Nakajima, T., Lavenu, F., Jankowiak, I., and Smirnov, A. : AERONET - a federated instrument network and data archive for aerosol characterization, Remote Sens. Environ., 66, 1-16, 1998.

IPCC, 2007: Climate Change 2007: The Physical Science Basis, in: Contribution of Working Group I to the Fourth Assessment Report of the Intergovernmental Panel on Climate Change, edited by: Solomon, S., Qin, D., Manning, M., Chen, Z., Marquis, M., Averyt, K. B., Tignor, M., and Miller, H. L., Cambridge University Press, Cambridge, UK and New York, NY, USA, 996 pp., 2007.

Kalapureddy, M. C. R., Kaskaoutis, D. G., Ernest Raj, P., Devara, P. C. S., Kambezidis, H. D., Kosmopoulos, P. G., and Nastos, P. T.: Identification of aerosol type over the Arabian Sea in the premonsoon season during the Integrated Campaign for Aerosols, Gases and Radiation Budget (ICARB), J. Geophys. Res., 114, D17203, doi:10.1029/2009JD011826, 2009.

Kaskaoutis, D. G., Kambezidis, H. D., Hatzianastassiou, N., Kosmopoulos, P. G., and Badarinath, K. V. S.: Aerosol climatology: dependence of the Angstrom exponent on wavelength over four AERONET sites, Atmos. Chem. Phys. Discuss., 7, 7347-7397, doi:10.5194/acpd-7-7347-2007, 2007.

Kaufman, Y. J., Tanré, D., and Boucher, O.: A satellite view of aerosols in the climate system, Nature, 418, 215-223, 2002.

Lee, J., Kim, J., Song, C. H., Kim, S. B., Chun, Y., Sohn, B. J., and Holben, B. N.: Characteristics of aerosol types from AERONET sunphotometer measurements, Atmos. Environ., 44, 3110-3117, doi:10.1016/j.atmosenv.2010.05.035, 2010.

Lenoble, J., Herman, M., Deuzé, J. L., Lafrance, B., Santer, R., and Tanré, D.: A successive order of scattering code for solving the vector equation of transfer in the earth's atmosphere with aerosols, J. Quant. Spectrosc. Ra., 107, 479-507, 2007.

Leon, J. and Legrand, M.: Mineral dust sources in the surrounding of the North Indian Ocean, Geophys. Res. Lett., 30, 1309, doi:10.1029/2002GL016690, 2003.

Li, Z., Goloub, P., Devaux, C., Gu, X., Qiao, Y., Zhao, F., and Chene, H.: Aerosol polarized phase function and single-scattering albedo retrieved from groundbased measurements, Atmos. Res., 71, 233-241, 2004.

Li, Z., Goloub, P., Devaux, C., Gu, X., Qiao, Y., and Zhao, F.: Retrieval of aerosol optical and physical properties from groundbased spectral, multi-angular and polarized sun-photometer measurements, Remote Sens. Environ., 101, 519-533, 2006.
Li, Z., Goloub, P., Blarel, L., Damiri, B., Podvin, T., and Jankowiak, I.: Dust optical properties retrieved from groundbased polarimetric measurements, Appl. Optics, 46, 1548-1553, 2007.

Li, Z., Goloub, P., Dubovik, O., Blarel, L., Zhang, W., Podvin, T., Sinyuk, A., Sorokin, M., Chen, H., Holben, B., Tanré, D., Canini, M., and Buis, J.-P.: Improvements for ground-based remote sensing of atmospheric aerosol properties by additional polarimetric measurements, J. Quant. Spectrosc. Ra., 110, 19541961, 2009.

Liou, K. N.: An Introduction to Atmospheric Radiation, Academic Press, San Diego, CA, 2002.

Lucht, W. and Roujean, J. L.: Consideration in parametric modeling of BRDF and albedo from multi-angular satellite sensors observations, Remote Sens. Rev., 18, 343-379, 2000.

Masoumi, A., Khalesifard, H. R., Bayat, A., and Moradhaseli, R.: Retrieval of aerosol optical and physical properties from groundbased measurements for Zanjan, a city in Northwest Iran, Atmos. Res., 120-121, 343-355, 2013.

Michalsky, J. J.: The astronomical Almanac's algorithm for approximate solar position (1950-2050), Sol. Energy, 40, 227-235, 1988.

Mielonen, T., Arola, A., Komppula, M., Kukkonen, J., Koskinen, J., de Leeuw, G., and Lehtinen, K. E. J.: Comparison of CALIOP level 2 aerosol subtypes to aerosol types derived from AERONET inversion data, Geophys. Res. Lett., 36, L18804, doi:10.1029/2009GL039609, 2009.

Omar, A. H., Won, J.-G., Winker, D. M., Yoon, S.-C., Dubovik, O., and McCormick, M. P.: Development of global aerosol models using cluster analysis of Aerosol Robotic Network (AERONET) measurements, J. Geophys. Res., 110, D10S14, doi:10.1029/2004JD004874, 2005.

Prospero, J. M., Ginoux, P., Torres, O., Nicholson, S. E., and Gill, T. E.: Environmental characterization of global sources of atmospheric soil dust identified with the NIMBUS 7 Total Ozone Mapping Spectrometer (TOMS) absorbing aerosol product, Rev. Geophys., 40, 1002-1029, 2002.

Russell, P. B., Bergstrom, R. W., Shinozuka, Y., Clarke, A. D., DeCarlo, P. F., Jimenez, J. L., Livingston, J. M., Redemann, J., Dubovik, O., and Strawa, A.: Absorption Ångström Exponent in AERONET and related data as an indicator of aerosol composition, Atmos. Chem. Phys., 10, 1155-1169, doi:10.5194/acp-101155, 2010.

Sabetghadam, S., Ahmadi-Givi, F., and Golestani, Y.: Visibility trends in Tehran during 1958-2008, Atmos. Environ., 62, 512520, 2012.

Samimi, J. and Anvari, A.: Envestigation and Analysis of Solar Energy Information and its Potantioal in Iran, Tech. Report, Center for Energy Studies, Iran, Ministry of energy, Iran, 1997.

Siewert, C. E.: On the phase matrix basic to the scattering of polarized light, Astron. Astrophys., 109, 195-200, 1982.

Smirnov, A., Holben, B. N., Eck, T. F., Dubovik, O., and Slutsker, I.: Cloud Screening and quality control algorithms for the AERONET database, Remote Sens. Environ., 73, 337-349, 2000 .

Toledano, C., Cachorro, V. E., Berjon, A., de Frutos, A. M., Sorribas, M., de la Morena, B. A., and Goloub, P.: Aerosol optical depth and Ångström exponent climatology at "El Arenosillo" 
AERONET site (Huelva, Spain), Q. J. Roy. Meteor. Soc., 133, 795-807, 2007.

Van de Hulst, H. C.: Multiple Light Scattering. Tables, Formulas, and Applications, 2 Volumes, Academic Press, New York, 1980.

Vermeulen, A., Devaux, C., and Herman, M.: Retrieval of the scattering and microphysical properties of aerosols from groundbased optical measurements including polarization: I. Method, Appl. Optics, 39, 6207-6220, 2000.
Winker, D. M., Hunt, W. H., and McGill, M. J.: Initial performance assessment of CALIOP, Geophys. Res. Lett., 34, L19803, doi:10.1029/2007GL030135, 2007.

Zdunkowski, W., Trautmann, T., and Bott, A.: Radiation in the Atmosphere. A course in Theoretical Meteorology, Cambridge University Press, New York, 2007. 